\title{
Rafael Malpartida Tirado (coord.), Recepción y canon de la literatura española en el cine, Madrid, Síntesis, 2018.
}

Desde prácticamente la aparición de las artes es frecuente, casi instintivo, que el ser humano las compare entre sí. No obstante, esa comparativa suele guiarse por lastimosas cuestiones, influidas por automatismos y hábitos mentales, de jerarquía o de sumisión de unas sobre otras. Es el caso de la literatura, el gran arte, aquella que carga con el peso de toda una tradición cultural, en comparación con el cine, centenario y de carácter más popular, y que supuestamente -nada más lejos de la realidadle debe rendir una dolorosa pleitesía.

Una de las cuestiones más espinosas, por lo tanto, es la de las adaptaciones de la literatura al cine, ejercicio comparatista objeto de controvertidas opiniones, muchas veces lanzadas al dictado implacable del prejuicio. La publicación de un libro como Recepción y canon de la literatura española en el cine viene a cubrir un hueco en los estudios académicos sobre las relaciones de la literatura española con el cine. Su intención es cavar los cimientos para la creación de un canon de adaptaciones, abierto pero riguroso, y desprendido de cualquier relación de jerarquía.

Coordinado por Rafael Malpartida Tirado, profesor de la Universidad de Málaga, este libro colectivo supone un paso más en los estudios comparatistas. La trayectoria del profesor Malpartida está avalada por trabajos como «El secreto de sus ojos o cómo vivir una vida vacía: de la literatura al cine (Eduardo Sacheri/Juan José Campanella)» (Revista de crítica literaria latinoamericana, 2011), Espectros de cine en Japón: entre la literatura, la leyenda y las nuevas tecnologías (Gijón, Satori, 2014) o "Subjetividad y adhesión emocional en dos adaptaciones de la novela al cine» (Signa: Revista de la Asociación Española de Semiótica, 2015), entre otros muchos. Se trata, en consecuencia, de un investigador experimentado y de prestigio en el estudio de las adaptaciones de obras literarias al cine. Desde la órbita de la «estética de la recepción», base teórica de esta obra, lejos de jerarquizaciones oscuras e inútiles, propugna Malpartida en la «Presentación» una relación abierta y bidireccional entre las dos artes. Una correspondencia fecunda según la cual, según el autor, «al establecimiento o reajuste del canon literario ha contribuido también notablemente el hecho de que una obra se traslade al

Trasvases entre la literatura y el cine, I, 2019, págs. 221-226 
séptimo arte, de igual modo que un texto fílmico, si procede de guion adaptado, va bosquejando su lugar en el canon en función de la relación que establece con su venero de ideas» (pág. 11).

El libro está estructurado en cuatro partes. La primera, escrita por el profesor Malpartida, es un detallado estado de la cuestión y establecimiento de los principios metodológicos para un adecuado estudio de la fértil relación entre literatura y cine, y viceversa. A partir de ese primer bloque teórico, se establecen tres bloques más, con la intención de aproximarse al estudio de literatura y cine de una manera ordenada, a partir de los tres grandes géneros literarios: narrativa, teatro y poesía. Cada bloque, a su vez, cuenta con capítulos escritos por investigadores de renombre que aplican, así, los principios metodológicos establecidos en el primer apartado.

El estado de la cuestión descrito por el autor acerca de las relaciones literatura-cine es bastante grave, pero esperanzador. Aún predominan ideas anquilosadas, es decir, tópicos y prejuicios que navegan en ambos ámbitos, y que todavía esgrimen investigadores de talla reconocida. El listado de prejuicios es amplio, pero el autor los va desmontando, paso a paso. Cuestiones como la imaginación, la subjetividad, la fidelidad, el espíritu y las equivalencias, van cayendo por el peso de las argumentaciones. Y en no pocas ocasiones, el profesor Malpartida, mediante cierto tono cercano, casi irónico, no reñido con el rigor académico, pregunta directamente al lector. Lo provoca, lo incita, antes de desarrollar los argumentos que desmontan, uno por uno, todos los prejuicios, pues «en realidad cada ámbito artístico emplea sus propios recursos y las supuestas analogías son solo metafóricas» (pág. 28). Este libro plantea, al fin y al cabo, que son dos ámbitos artísticos que no están en pugna; no es una competición de valor, sino de afinidades o de «intersección de universos», como afirma Sergio Wolf.

Ahora bien, ante este panorama, ¿cómo plantear entonces el estudio de los trasvases de la literatura al cine? Según el autor, el principal reto consiste en «analizar la conjunción de elementos que, junto con el hecho de que se esté adaptando un texto literario, contribuyen a que el filme cristalice» (pág. 48). Así, estudiada la literatura como un factor más entre múltiples estímulos, cada texto, el literario y el fílmico, es responsable de sus méritos y deméritos, que no se deben «a supuestos y abstracciones ya previstos en modelos taxonómicos y analíticos» (pág. 50). En resumidas cuentas, se trata de un viaje del prejuicio al juicio.

Además de estos sólidos planteamientos teóricos establecidos en el primer bloque, apuntalados por una extensa bibliografía, este libro destaca por las aportaciones del resto de los autores, que ejecutan de manera consecuente los replanteamientos metodológicos del coordinador. Así, en el siguiente bloque, dedicado a las relaciones entre la narrativa española y el cine, Lucía Morillo, investigadora de la Universidad de Málaga, analiza la 
recepción de las películas Fin (Jorge Torregrossa, 2012) y Extinción (Miguel Ángel Vivas, 2015), adaptaciones de las novelas de David Monteagudo y Juan de Dios Garduño, respectivamente. Contrasta la recepción positiva de las novelas con las críticas muy negativas de las dos películas. En el caso de las novelas, pese a considerarse de ciencia-ficción, los lectores permiten una mayor apertura de miras, una mayor indeterminación y suspense, incluso cierta incomprensión, «un claroscuro semántico esencial para la comprensión del texto literario y de la película» (págs. 73-74). Sin embargo, la recepción de los espectadores es negativa en comparación con los lectores. Una de las hipótesis de Lucía Morillo es que los horizontes de expectativas del lector y el espectador son distintos, sobre todo por cuestiones como la publicidad y la exposición de la película en Internet, lo que sería comparable a lo que afirma Sullá: «la interpretación asegura la vida de una obra» (pág. 35). Toda recepción es generación de sentido, está condicionada por factores externos a la obra artística que deben analizarse, algo que conecta directamente con el carácter colectivo del cine: productores, actores, directores, críticos y el público receptor. Es muy acertada, por lo tanto, la inclusión de un apartado de críticas de páginas web junto con la bibliografía académica.

Por otra parte, en el mismo bloque de narrativa y cine, José Manuel Herrera, investigador de la Universidad de Málaga, estudia la recepción entre público y crítica de La pasión turca (Vicente Aranda, 1994), adaptación de la novela de Antonio Gala. Sus planteamientos son reveladores: «Podríamos interrogarnos acerca de si la crítica popular no carga las tintas contra el aspecto más llamativo de la película debido a un conflicto con su horizonte de expectativas», en vez de considerar cuestiones técnicas de la narración fílmica, lo que impide mostrar «una pasión al límite en la búsqueda de la libertad sexual de la protagonista» (pág. 89). En conclusión, nuestra sociedad no está aún preparada del todo para aceptar la libertad sexual de la mujer, tema controvertido que se remonta a textos antiguos como Gilgamesh, y que se refleja en la recepción de una película como esta y sus críticas negativas - extrapolables a la novela-, que contrastan con las cifras de espectadores y venta millonaria de ejemplares. José Manuel Herrera, además, de manera acertada, deja abierto el estudio a nuevos ejemplos literarios y cinematográficos sobre erotismo, sexualidad y su recepción, donde también incluye con acierto un apartado de críticas de páginas web, que contrastan con su reconocida bibliografía, no solo en relación con la literatura y el cine, también con la filosofía.

En el tercer apartado del bloque sobre narrativa y cine, Carlos A. Cuéllar, profesor de la Universidad de Valencia, profundiza en la relación entre literatura y cine, pero a la inversa: la adaptación de una película a novela. Es decir, se trata de una simbiosis interdisciplinar, y la ejemplifica 
en la figura de un artista de culto, Jacinto Molina, conocido como Paul Naschy. El multifacético Molina, productor, actor, guionista y escritor de la novela Alaric de Marnac (2009), se convirtió en un referente en los círculos underground, sobre todo entre los aficionados al cine de terror, lo que contrasta con su nula presencia en la historiografía oficial, y que le permitió adaptar su película a novela con toda la libertad, «un ejemplo de continuidad en el capítulo final de una carrera creativa caracterizada por el crossover desde el punto de vista genérico» (pág. 99). Se trata de una muestra clara de la complementariedad de ambas disciplinas artísticas, y que con obras rigurosas y de calidad podría fomentar el consumo interdisciplinar: el cine como fomento de la lectura y al contrario.

El siguiente género que se estudia en el libro es el teatro. Destaca el extenso capítulo dedicado al teatro español y el cine en una época histórica crucial, la llamada Transición. Pablo Pérez Rubio, profesor del IES San José de Cuenca, cuya aportación de datos y argumentos en relación con el contexto histórico es brillante, alcanza una conclusión demoledora: se concibe aquella época como de apertura, luminosa, esperanzadora, pero esa concepción popular choca con la evolución disímil entre teatro y cine. El teatro es el receptáculo de los valores tradicionales en contraposición con el cine, que estaba abierto a todo tipo de propuestas. Según el autor, «se dieron la espalda» (pág. 136), parecieron encarnar valores opuestos, y aún hoy parece ser una tendencia, pero con excepciones.

Una de esas salvedades, y que enlaza con la idea de fomento de unas artes mediante otras, es el análisis de Manuel España Arjona, profesor de la Bergische Universität Wuppertal, de El perro del hortelano, la obra teatral de Lope de Vega que adaptó al cine Pilar Miró. La aportación del autor es esencial para comprender, por ejemplo, cómo funciona el canon y su construcción. En el caso de Lope de Vega, es llamativo que sus obras apenas se representaran durante el Siglo de Oro, y que su encumbramiento fuese posterior, gracias a la labor de críticos como Menéndez Pelayo. Una canonización a la que contribuyó, asimismo, años después, de manera inesperada, la película de Pilar Miró, que granjeó una gran atención editorial a Lope tras la proyección de El perro del hortelano y una «popularización» de todas las obras del autor. Éxito fílmico que se ha convertido en pieza esencial de la formación académica de muchos alumnos por encima del texto literario, provocando su «capitalización cultural», entre otras cuestiones.

El último bloque supone una inmersión en las relaciones entre la poesía y el cine, que no son meras adaptaciones, y muestra lo fértiles que llegan a ser los intercambios, no solo la mera transposición. Es una relación absolutamente artística, dinámica y abierta. Luis Bagué, profesor de la Universidad de Murcia, analiza la parte más rebelde del canon, aquella en que relaciona Arrebato (Iván Zulueta, 1979) con las obras poéticas de Aníbal 
Núñez y Javier Egea. Establece una relación mediante tres metáforas esenciales: la adicción, la casa tomada y el tránsito al otro lado del espejo. Sus conclusiones son la existencia del llamado «canon adicto», aquel en el que confluyen un cine y una poesía de fuertes tintes ideológicos y con ramificaciones en la experimentación con sustancias a lo Charles Baudelaire. Canon, por otra parte, formado en las periferias críticas y sociales, y cuya leyenda se ha visto acrecentada por las muertes prematuras de los tres protagonistas.

Si existe una familia con ciertos aires míticos en la literatura española es la de los Panero. Antonio J. Quesada, profesor de la Universidad de Málaga, disecciona la influencia que ha ejercido el cine sobre la imagen popular de Felicidad Blanch y sus hijos Leopoldo María, Juan Luis y Michi, con la presencia fantasmal del fallecido padre Leopoldo Panero, conocido como el poeta oficial del franquismo. Con minuciosidad y precisión en los datos y argumentos, Quesada analiza la influencia de las películas El desencanto (Jaime Chávarri, 1976) y Después de tantos años (Ricardo Franco, 1994), que supusieron un antes y un después para los Panero, que son más conocidos por la película que por sus obras. Toda una declaración acerca de la importancia, del impacto del cine, que se convierte, al mismo tiempo, en herramienta de interpretación de las obras literarias de los Panero. Es decir, los Panero no serían los que son sin las películas, un imaginario popular que se construyó con cine, exposición mediática y literatura. Una literatura que, a su vez, influye de manera decisiva en la construcción de la imagen. Sin ella no existirían los Panero como figuras del universo popular, como iconos pop.

Si aplicamos una mirada de conjunto, uno de los grandes aciertos de este libro es su disposición ordenada en bloques temáticos, además de su enfoque colectivo, su rigor bibliográfico y la apertura a novedosas fuentes de investigación como las críticas en páginas web. Partiendo así de unos sólidos postulados teóricos y metodológicos, se establecen los fundamentos para el estudio académico de un canon de adaptaciones literarias al cine, que será extenso y de acervo enriquecedor. Así, podrían dejarse atrás las trilladas listas de obras maestras que son adaptaciones de obras literarias para centrarse en un criterio sencillo, pero que muchas veces se olvida: el cine y la literatura se deben a los aciertos y errores respectivos a la hora de narrar una historia nueva, y no a supuestos débitos trazados de antemano. Es tarea de los investigadores -en este libro son ejemplares- romper con esos prejuicios, con cuestiones abstractas y formuladas a priori. En lugar de indagarse en lo que el cine podría o debería hacer con la literatura, convendría analizarse lo que aporta de facto cada película, sin obviar, por supuesto, los nuevos elementos que surjan en el proceso, como indica el coordinador del libro en el primer bloque. El objetivo es alcanzar un juicio acerca de la 


\section{Carlos G. Pranger}

creación final en sí misma. Así, analizar una adaptación, como afirma el profesor Malpartida, consiste en preguntarse si se notan «las costuras» (pág. 50) cuando se importan elementos de otro medio.

A este libro colectivo no se le ven las costuras. Es más, el enfoque y las conclusiones vaticinan una continuación de esta brillante línea de investigación, a la que habría de añadírsele otros géneros como el cuento, el ensayo e incluso el microrrelato. Claudio Guillén, uno de los grandes comparatistas españoles, en su aclamado libro Entre lo uno y lo diverso citaba a José Ferrater Mora, quien pensaba «que las realidades consideradas por ciertas filosofías como absolutas son en rigor términos finales de ciertas tendencias, nunca alcanzadas de manera total o definitiva» (Barcelona, Tusquets, 2015, pág. 27). Es indudable que Recepción y canon de la literatura española en el cine es solo el comienzo de un hipotexto que seguirá ofreciendo jugosos hipertextos en el futuro.

CARlos G. Pranger

Universidad de Almería 